\title{
Predictive value of procalcitonin decrease in patients with severe sepsis: a prospective observational study
}

\author{
Sari Karlsson ${ }^{1 *}$, Milja Heikkinen², Ville Pettilä ${ }^{3}$, Seija Alila ${ }^{4}$, Sari Väisänen², Kari Pulkki², Elina Kolho ${ }^{5}$, Esko Ruokonen ${ }^{6}$, \\ the Finnsepsis Study Group ${ }^{1}$
}

\begin{abstract}
Introduction: This prospective study investigated the predictive value of procalcitonin (PCT) for survival in 242 adult patients with severe sepsis and septic shock treated in intensive care.

Methods: PCT was analyzed from blood samples of all patients at baseline, and 155 patients 72 hours later.

Results: The median PCT serum concentration on day 0 was $5.0 \mathrm{ng} / \mathrm{ml}$ (interquartile range (IQR) 1.0 and $20.1 \mathrm{ng} / \mathrm{ml}$ ) and $1.3 \mathrm{ng} / \mathrm{ml}$ (IQR 0.5 and $5.8 \mathrm{ng} / \mathrm{ml}$ ) 72 hours later. Hospital mortality was 25.6\% (62/242). Median PCT concentrations in patients with community-acquired infections were higher than with nosocomial infections $(\mathrm{P}=$ 0.001). Blood cultures were positive in $28.5 \%$ of patients $(n=69)$, and severe sepsis with positive blood cultures was associated with higher PCT levels than with negative cultures $(P=<0.001)$. Patients with septic shock had higher $P C T$ concentrations than patients without $(P=0.02)$. $P C T$ concentrations did not differ between hospital survivors and nonsurvivors ( $P=0.64$ and $P=0.99$, respectively), but mortality was lower in patients whose $P C T$ concentration decreased $>50 \%$ (by 72 hours) compared to those with a $<50 \%$ decrease $(12.2 \%$ vs. $29.8 \%, P=0.007)$.
\end{abstract}

Conclusions: PCT concentrations were higher in more severe forms of severe sepsis, but a substantial concentration decrease was more important for survival than absolute values.

\section{Introduction}

Because promptly administered antimicrobial and early goal-directed treatment has been shown to improve outcome in patients with severe sepsis [1,2], early recognition of infection as a cause of critical illness is of major importance. Various biomarkers, such as C-reactive protein (CRP), interleukin-6 (IL-6), and triggering receptor expressed on myeloid cells-1 (TREM-1), have been studied as a means of detecting infection as a cause of systemic inflammation response syndrome, but none has been shown to be used reliably to diagnose sepsis [3]. In addition, CRP and other biomarkers have not been shown to detect patients with a high risk of poor outcome [4].

\footnotetext{
* Correspondence: sari.karlsson@pshp.fi

'Department of Intensive Care Medicine, Tampere University Hospital,

Teiskontie 35, 33521 Tampere, Finland Full list of author information is available at the end of the article
}

Procalcitonin (PCT) is a 116-amino acid prohormone of calcitonin [5] that is found in the bloodstream without changes in the total amount of calcitonin [6]. The production of PCT is stimulated by inflammatory cytokines, such as tumor necrosis factor-alpha and IL-6 [7]. PCT concentrations increase after bacterial infection but also in noninfectious conditions with systemic inflammation, such as multiple trauma, cardiogenic shock, induction of hypothermia after cardiac arrest, and drug sensitivity reactions [8-11]. PCT concentrations are also elevated after major surgery [12]. However, bacterial infections increase the expression of the PCT-producing $C A L C-1$ gene in multiple extrathyroid tissues throughout the body [13].

Patients without infection and inflammation usually have low serum PCT concentrations $(<0.05 \mathrm{ng} / \mathrm{mL})$. In patients with severe sepsis or septic shock, PCT concentrations may increase significantly (up to $1,000 \mathrm{ng} / \mathrm{mL}$ ) [5]. The cutoff value for sepsis has been set at 0.44 to
C Biomed Central 
$1.0 \mathrm{ng} / \mathrm{mL}$ in different studies $[14,15]$. PCT concentrations have been used to differentiate noninfected patients from infected patients in prospective clinical studies, and higher mortality has been associated with patients who have increasing or persistently high PCT concentrations [16]. Recent studies concerning PCT have focused on patients with suspected or verified bacterial infections, and the duration of antibiotic treatment was guided by decreasing PCT concentrations [17-19]. Reduced antibiotic administration without increased adverse outcomes has been shown in patients with lower respiratory tract infections (LRTIs) [18], medical intensive care unit (ICU) patients [19], and patients with severe sepsis and septic shock [20].

Meta-analyses of PCT have produced conflicting results. One study concluded that PCT measurement cannot differentiate sepsis reliably from other causes of systemic inflammatory response syndrome and should not be used widely in a critical care setting [21]. In contrast, another study regarded PCT as superior to CRP measurement and concluded that PCT should be used to diagnose sepsis in ICUs [22]. Differences in the case mix may contribute to the varying results in critical care settings: on admission to the hospital or ICU, patients are at different phases in the course of their sepsis; preceding antibiotic treatment may be absent, ineffective [23], or delayed [1]; and in postoperative patients, the type of surgery may influence PCT concentrations [24].

In the present study, we measured PCT concentrations twice in adult ICU patients with clinically diagnosed severe sepsis in the first 3 days after diagnosis. We evaluated PCT concentrations and the type of organ dysfunction, the type of infection (blood culture-positive, community-acquired, or nosocomial), and the predictive value for outcome of the first PCT concentration and the decrease in PCT after treatment in this large population of patients with severe sepsis.

\section{Materials and methods Patient selection}

This study was part of the Finnsepsis study, a prospective observational cohort study of incidence and outcome of severe sepsis in Finland [25]. All adult consecutive ICU admission episodes $(4,500)$ in 24 ICUs were screened for severe sepsis in a 4-month period (from 1 November 2004 to 28 February 2005). Patients were eligible if they fulfilled the American College of Chest Physicians/Society of Critical Care Medicine (ACCP/SCCM) criteria for severe sepsis or septic shock [26]. Study entry (day 0) was the time when these criteria were first met. Consent from the ethics committee was granted from each hospital. All patients or their next of kin gave written consent for the study. APACHE II (Acute Physiology and Chronic Health Evaluation II) score and SAPS II (Simplified Acute Physiology Score II) $[27,28]$, organ dysfunction evaluated with SOFA (Sequential Organ Failure Assessment) score, maximum SOFA scores $[29,30]$, and ICU and hospital mortalities were recorded. Septic shock was defined as cardiovascular SOFA score 4, and acute kidney injury was defined as renal SOFA score 3 or 4 . Severe sepsis was defined as community-acquired if the infection was present or suspected at hospital admission or less than 48 hours thereafter and was defined as nosocomial if the infection was diagnosed at least 48 hours after hospital admission. Blood CRP concentrations were analyzed as daily routine samples in each participating hospital. Blood cultures were drawn when clinically indicated and were analyzed locally.

\section{Blood samples}

Arterial blood samples for PCT analyses were drawn after informed consent within 24 hours of study entry (day 0) and 72 hours thereafter. The reason for exclusion was failure to obtain consent. Blood for serum samples was collected, and the samples were prepared within 60 minutes of sampling. The samples were stored at $-80^{\circ} \mathrm{C}$ for later analysis. Serum PCT levels were measured with the Cobas 6000 analyzer (Hitachi High-Technologies Corporation, Tokyo, Japan). Analyzer reagents (Elecsys B.R.A.H.M.S PCT assay) were developed in collaboration with B.R.A.H.M.S Aktiengesellschaft (Hennigsdorf, Germany) and Roche Diagnostics (Mannheim, Germany). The functional assay sensitivity (that is, the lowest concentration that can be quantified with a between-run imprecision of 20\%) met the Roche Diagnostics specification of $0.06 \mathrm{ng} / \mathrm{mL}$. The respective within- and between-day coefficients of variation for PCT analyses were $1.4 \%$ and $3.0 \%$ for $0.46 \mathrm{ng} / \mathrm{mL}$ PCT and $1.1 \%$ and $2.6 \%$ for $9.4 \mathrm{ng} / \mathrm{mL}$ PCT.

\section{Statistical analyses}

Data are presented as median and interquartile range (IQR) (25th to 75th percentiles), absolute value and percentage, or mean \pm standard deviation. The nonparametric data between survivors and nonsurvivors were compared with the Mann-Whitney $U$ test, and categorical variables were compared with the chi-square test. PCT kinetics are expressed as delta PCT $(\triangle \mathrm{PCT})$ concentrations. $\triangle \mathrm{PCT}$ was calculated as the difference between concentrations on day 0 and 72 hours (day 0 to 72 hours). $\triangle \mathrm{PCT}$ was positive with decreasing concentrations and negative with increasing concentrations. The level of change between the two samples (for example, greater than $50 \%$ ) was calculated as a proportion of $\triangle \mathrm{PCT} / \mathrm{PCT}$ on day 0 . The sensitivity, specificity, and positive likelihood ratio for different PCT cutoff levels were calculated. To determine the prognostic accuracy 
of PCT and CRP on both time points, receiver operating characteristic (ROC) curves were constructed and the areas under the curve (AUCs) were calculated with 95\% confidence intervals (CIs). A $P$ value of less than 0.05 was considered to be statistically significant in all tests. The analyses were performed using SPSS 17.0 software (SPSS Inc., Chicago, IL, USA).

\section{Results}

Informed consent and blood samples for the PCT analyses were obtained from 242 out of 470 patients (51.2\%) of the Finnsepsis study population. Two hundred forty-two samples were obtained at baseline (day 0 ); of these, 155 samples were available 72 hours later. Fourteen patients died and 13 were discharged from the ICU before the second sample was obtained. Owing to logistical reasons, an additional 59 samples were not available.

The flowchart of the study is presented in Figure 1. The patients were divided by the type of infection and the cutoff concentration for PCT to detect unlikely sepsis $(<0.5 \mathrm{ng} / \mathrm{mL})$ in semiquantitative PCT measurements (PCT-Q test) [31]. Age, gender, APACHE II score, SAPS II, maximum SOFA score, ICU mortalities, and hospital mortalities did not differ from the Finnsepsis patients who did not have PCT analyses $(P=0.75$, $0.63,0.58,0.35,0.22,024$, and 0.18 , respectively). The infection and mortality data of patients with community-acquired or nosocomial severe sepsis are presented in Table 1. Mortality in patients with positive blood cultures did not differ from patients with blood culturenegative infections $(26.1 \%$ and $25.4 \%$, respectively; $P=$ $0.92)$. Hospital mortality of patients with severe septic shock (cardiovascular SOFA score 4) was higher than

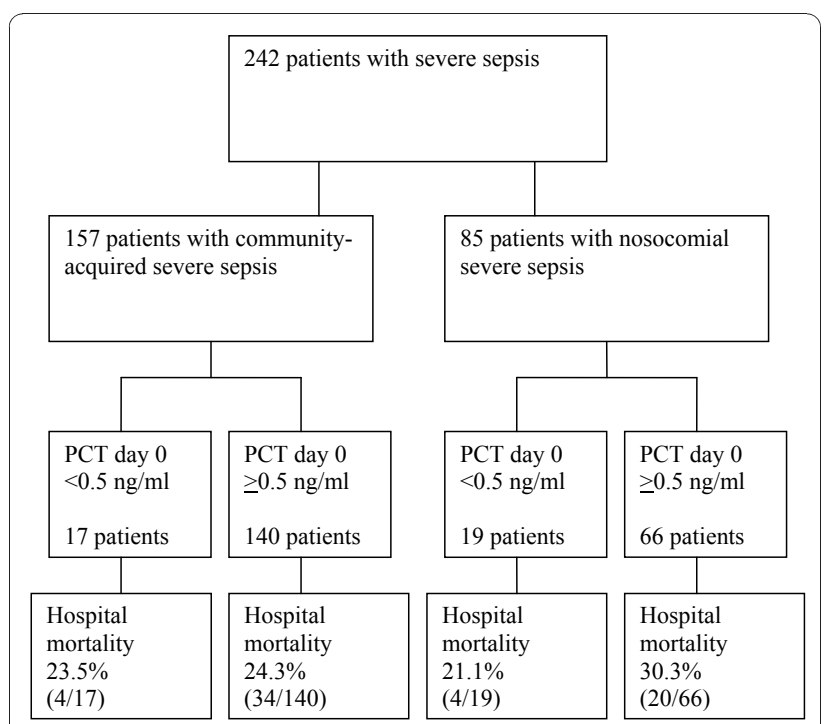

Figure 1 Flowchart of the study. PCT, procalcitonin. that of patients with less severe or absent cardiovascular failure (31.6\% versus $22.4 \%, P=0.015)$.

\section{Procalcitonin concentrations}

The median PCT concentrations in patients with severe sepsis are presented in Table 2 . On day 0 , the range varied from 0.02 to $261.9 \mathrm{ng} / \mathrm{mL}$, and after 72 hours, the range varied from 0.03 to $439 \mathrm{ng} / \mathrm{mL}$. PCT concentrations did not differ between hospital survivors and nonsurvivors at either time point $(P=0.64$ and $P=0.99$ for day 0 and 72 hours, respectively). The ROC curves for day-0 and 72-hour PCT concentrations and mortality showed AUCs of 0.42 (95\% CI 0.31 to $0.54, P=0.19$ ) and 0.50 (95\% CI 0.38 to $0.62, P=0.99$ ), respectively. High PCT concentrations (PCT $>10 \mathrm{ng} / \mathrm{mL}$ ) on day 0 or 72 hours did not predict mortality; AUCs were 0.58 (CI 0.43 to $0.73, P=0.25$ ) and 0.36 (CI 0.09 to $0.62, P=$ $0.33)$, respectively.

\section{Procalcitonin and type of infection}

The median PCT concentrations on day 0 and after 72 hours in patients with community-acquired infections were higher than in patients with nosocomial infections ( $P=0.001$ and $P=0.003$, respectively) (Figure 2 ). Blood cultures were drawn from 160 out of 242 patients $(66 \%)$ and were positive in 69 out of 242 (28.5\%). PCT concentrations in relation to blood cultures and communityacquired or nosocomial infections are presented in Table 2. PCT concentrations were higher in patients with positive blood cultures at both time points $(P<0.001$ and $P<0.001$, respectively). The ROC curves for day- 0 and 72-hour PCT concentrations predicted blood culture-positive infections, with AUCs of 0.76 (95\% CI 0.66 to $0.86, P<0.001)$ and $0.74(95 \% \mathrm{CI} 0.64$ to $0.84, P<$ 0.001 ) (Figure 3 ). The cutoff PCT concentration for blood culture-positive infection with $90 \%$ sensitivity (95\% CI $83 \%$ to $97 \%$ ) was $1.2 \mathrm{ng} / \mathrm{mL}$. The positive likelihood ratio was 1.4 (95\% CI 1.2 to 1.6$)$. The cutoff PCT concentration of $10 \mathrm{ng} / \mathrm{mL}$ had $62 \%$ (95\% CI 51\% to $74 \%$ ) sensitivity and $73 \%$ (95\% CI $63 \%$ to $82 \%$ ) specificity with a positive likelihood ratio of 2.3 (95\% CI 1.5 to 3.3 ) for positive blood culture. PCT of greater than $20 \mathrm{ng} / \mathrm{mL}$ had $85 \%$ specificity ( $95 \%$ CI $77 \%$ to $92 \%$ ), and the positive likelihood ratio was 3 (95\% CI 1.7 to 5.2 ).

Thirty-six patients with clinically diagnosed severe sepsis and low PCT concentrations ('sepsis unlikely') had median PCT concentrations of $0.17 \mathrm{ng} / \mathrm{mL}$ (IQR 0.93 and $0.27 \mathrm{ng} / \mathrm{mL}$ ) on day 0 and $0.13 \mathrm{ng} / \mathrm{mL}$ (IQR 0.08 and $0.22 \mathrm{ng} / \mathrm{mL}$ ). Only one patient had a strongly increasing PCT of $17.88 \mathrm{ng} / \mathrm{mL}$ after 72 hours. The patient had an intra-abdominal infection. Nosocomial infection was found in 53\% (19/36) of these patients, and the sources of infection were the lungs in $44 \%$ $(16 / 36)$ and intra-abdominal in $31 \%(11 / 36)$. One patient 
Table 1 Patient data for all study patients and different types of infections

\begin{tabular}{|c|c|c|c|c|}
\hline & All patients & Community-acquired & Nosocomial & $P$ value \\
\hline Number of patients & 242 & $157 / 242(64.9 \%)$ & $85 / 242(35.1 \%)$ & $<0.001$ \\
\hline Age in years (SD) & $59.8(15.4)$ & $58.2(15.6)$ & $62.7(14.7)$ & 0.03 \\
\hline Males (percentage) & $165(68.2 \%)$ & $109(69.4 \%)$ & $56(65.9 \%)$ & 0.57 \\
\hline APACHE II score (SD) & $24.0(9.0)$ & $23.9(8.8)$ & $24.1(9.5)$ & 0.93 \\
\hline SAPS ॥ (SD) & $43.8(16.8)$ & $42.6(16.0)$ & $46.1(17.9)$ & 0.22 \\
\hline SOFA on day $1^{a}$ (SD) & $8.4(3.6)$ & $8.5(3.6)$ & $8.2(3.5)$ & 0.74 \\
\hline SOFAmax ${ }^{\mathrm{b}}$ (SD) & $10.9(4.3)$ & $11.0(4.4)$ & $10.7(4.1)$ & 0.68 \\
\hline Postoperative (percentage) & $63(26.0 \%)$ & $31(19.7 \%)$ & $32(37.6 \%)$ & $<0.01$ \\
\hline Chronic renal failure & $4(1.7 \%)$ & $1(0.6 \%)$ & $3(3.5 \%)$ & 0.16 \\
\hline Chronic lung disease & $25(10.3 \%)$ & $17(10.8 \%)$ & $8(9.4 \%)$ & 0.84 \\
\hline Chronic hepatic disease & $13(5.4 \%)$ & $6(3.8 \%)$ & $7(8.2 \%)$ & 0.22 \\
\hline Immunosuppression & $30(12.4 \%)$ & $20(12.7 \%)$ & $10(11.7 \%)$ & 0.80 \\
\hline ICU mortality & $33 / 242(13.6 \%)$ & 20/157 (12.7\%) & 13/85 (15.3\%) & 0.58 \\
\hline Hospital mortality & $62 / 242(25.6 \%)$ & $38 / 157$ (24.2\%) & 24/85 (28.2\%) & 0.49 \\
\hline \multicolumn{5}{|l|}{ Source of infection } \\
\hline Pulmonary & $101(41.7 \%)$ & 69 (43.9\%) & $32(37.6 \%)$ & 0.34 \\
\hline Intra-abdominal & 77 (31.9\%) & $42(26.8 \%)$ & $35(41.2 \%)$ & 0.02 \\
\hline Skin or soft tissue & $24(9.9 \%)$ & 17 (10.8\%) & 7 (8.2\%) & 0.52 \\
\hline Urinary tract & $11(4.5 \%)$ & $8(5.1 \%)$ & $3(3.5 \%)$ & 0.58 \\
\hline Other & $33(13.6 \%)$ & $24(15.3 \%)$ & $9(10.6 \%)$ & 0.31 \\
\hline \multicolumn{5}{|l|}{ Blood cultures } \\
\hline Blood cultures taken & $160 / 242(66.1 \%)$ & 110/157 (70.1\%) & 49/85 (57.6\%) & \\
\hline Positive blood cultures & $69 / 160(43.1 \%)$ & $56 / 110(50.9 \%)$ & $13 / 49(26.5 \%)$ & \\
\hline \multicolumn{5}{|l|}{$\begin{array}{l}\text { Microbes in positive } \\
\text { blood cultures }\end{array}$} \\
\hline Streptococcus pneumoniae & 13 & 13 & 0 & \\
\hline Staphylococcus aureus & 11 & 10 & 1 & \\
\hline Streptococcus species & 9 & 9 & 0 & \\
\hline Other Gram-positive & 4 & 4 & 0 & \\
\hline Escherichia coli & 14 & 11 & 3 & \\
\hline Other Gram-negative & 13 & 8 & 5 & \\
\hline Yeasts & 4 & 1 & 3 & \\
\hline Mycobacterium & 1 & 0 & 1 & \\
\hline $\begin{array}{l}\text { Ongoing antibiotic } \\
\text { treatment before day } 0\end{array}$ & $98 / 242(40.5 \%)$ & $38(24.2 \%)$ & $60(70.6 \%)$ & $<0.001$ \\
\hline
\end{tabular}

$P$ values refer to patients with community-acquired or nosocomial infections. ${ }^{a}$ Sequential Organ Failure Assessment score on the day after study entry. ${ }^{b}$ Maximum Sequential Organ Failure Assessment score. APACHE II, Acute Physiology and Chronic Health Evaluation II; ICU, intensive care unit; SAPS II, Simplified Acute Physiology Score II; SD, standard deviation.

had a blood culture-positive infection, and 14 other patients had significant microbial growths.

\section{Procalcitonin and organ dysfunction}

Patients with septic shock or acute kidney injury also had significantly higher PCT concentrations on day 0 compared with patients with milder or absent organ dysfunction $(P=0.020$ and $P=0.027$, respectively) (Table 2). When patients with two available PCT samples $(n=155)$ were divided into two groups according to decreasing PCT $(n=130)$ or increasing PCT $(n=$ $25)$, no significant differences were found in organ dysfunction $(P=0.58)$.

\section{Changes in procalcitonin concentrations}

We analyzed the difference in PCT concentrations on day 0 and 72 hours $(\triangle \mathrm{PCT})$ for the 155 patients with two blood samples available. The PCT concentration 
Table 2 Procalcitonin concentrations in different patient groups

\begin{tabular}{lcc}
\hline & \multicolumn{2}{c}{ Procalcitonin, $\mathbf{n g} / \mathbf{m L}$} \\
& \multicolumn{1}{c}{ Day 0 } & $\mathbf{7 2}$ hours \\
\hline All patients & $5.0(1.0-20.1)$ & $1.3(0.5-5.8)$ \\
Septic shock (SOFA 4) $^{\mathrm{a}}$ & $6.5(1.6-29.0)$ & $2.3(0.7-7.4)$ \\
$\begin{array}{l}\text { Without septic shock } \\
\text { (SOFA 0-3) }^{\mathrm{a}}\end{array}$ & $3.2(0.9-14.7)$ & $1.1(0.3-4.4)$ \\
$\begin{array}{l}\text { Severe acute kidney injury } \\
\text { (SOFA 3-4) }^{\mathrm{b}}\end{array}$ & $9.4(2.4-38.2)$ & $4.9(0.9-9.5)$ \\
$\begin{array}{l}\text { Without severe acute kidney } \\
\text { injury (SOFA 0-2) }\end{array}$ & $4.3(0.9-16.4)$ & $1.2(0.3-4.9)$ \\
$\begin{array}{l}\text { Blood culture-positive } \\
\text { infection }\end{array}$ & $15.6(4.3-43.6)$ & $5.2(1.7-8.7)$ \\
$\begin{array}{l}\text { Blood culture-negative } \\
\text { infection }\end{array}$ & & \\
Community-acquired infection $^{\mathrm{d}}$ & $6.6(1.4-33.2)$ & $2.4(0.7-6.5)$ \\
Nosocomial infection $^{d}$ & $2.9(0.8-10.6)$ & $0.9(0.2-2.8)$
\end{tabular}

The data are presented as median (interquartile range). $P$ values refer to differences between patient groups (for example, those with and those without septic shock). ${ }^{a} P=0.020$ on day 0 and $P=0.031$ at 72 hours; $P=$ 0.027 on day 0 and $P=0.02$ at 72 hours; $P<0.001$ on day 0 and $P<0.001$ at 72 hours; ${ }^{d} P=0.001$ on day 0 and $P=0.003$ at 72 hours. SOFA, Sequential Organ Failure Assessment.

decreased in 130 patients and increased in the remaining 25 patients, but the change in PCT concentration was not associated with mortality $(P=0.25)$. Of the patients with decreasing PCT concentrations, $66 \%$ $(86 / 130)$ had community-acquired infections and $34 \%$ $(44 / 130)$ had nosocomial infections $(P=0.014)$.

When the decreases in PCT concentrations were divided into arbitrary classes from greater than $50 \%$ to greater than $90 \%$, a substantial decrease in PCT concentration of greater than $50 \%$ between the first and second time points had an effect on hospital survival (Figure 4). The hospital mortality in patients with a greater than $50 \%$ decrease in PCT was 12.2\% (12/98) compared with $29.8 \%(17 / 57)$ in patients with a less than $50 \%$ decrease $(P=0.007)$. Community-acquired infections $(69.8 \%$, $67 / 96)$ were associated with a greater than $50 \%$ decrease more often than nosocomial infections were $(52.5 \%$, $31 / 59 ; P=0.031$ ). In patients with community-acquired severe sepsis, a greater than $50 \%$ decrease was associated with better outcome (62.5\% survivors) compared with patients with less than $50 \%$ decrease $(19.8 \%$ survivors, $P=0.05)$. However, this association was not present for patients with nosocomial severe sepsis $(P=0.40)$. In all patients with available $\triangle \mathrm{PCT}(n=155)$, a greater than $50 \%$ PCT decrease showed a poor AUC of 0.52 (95\% CI 0.36 to 0.68 ). The PCT decrease of greater than $50 \%$ was not independently associated with in-hospital mortality $(P=0.47$, odds ratio $0.99,95 \%$ CI 0.96 to 1.02$)$ either.

\section{C-reactive protein measurements}

The median CRP concentrations of this study population were $197 \mathrm{mg} / \mathrm{L}(104$ and $294 \mathrm{mg} / \mathrm{L})$ on day 0 and $149 \mathrm{mg} / \mathrm{L}$ (76 and $201 \mathrm{mg} / \mathrm{L}$ ) after 72 hours. Patients with positive blood cultures had higher day-0 CRP concentrations compared with patients with negative cultures $(244 \mathrm{mg} / \mathrm{L}$ [131 to $325 \mathrm{mg} / \mathrm{mL}$ ] and $187 \mathrm{mg} / \mathrm{L}$ [89 to $273 \mathrm{mg} / \mathrm{L}$, respectively; $P=0.016$ ). For patients with decreasing or increasing PCT concentrations, the CRP levels did not differ significantly on day 0 or after 72 hours $(P=0.138$ and $P=0.552$, respectively). CRP concentrations were not associated with the severity of cardiovascular dysfunction $(P=0.35$ and $P=0.11$ for day 0 and 72 hours, respectively). The ROC curves for day-0 and 72-hour CRP concentrations and mortality showed inadequate AUCs of 0.52 (95\% CI 0.46 to 0.58 ) and 0.59 (95\% CI 0.53 to 0.65$)$, respectively $(P=0.99)$.

\section{Discussion}

PCT concentrations varied largely among individual ICU patients with clinically diagnosed severe sepsis. The predictive value of the individual PCT samples for mortality was poor, but a prompt $50 \%$ decrease in PCT indicating resolving infection was associated with a favorable outcome. Patients with community-acquired infections had higher PCT concentrations compared with patients with nosocomial infections. PCT concentrations were not superior to CRP concentrations for predicting mortality or severity of illness in our study.

The high values (up to $439 \mathrm{ng} / \mathrm{mL}$ ) of the PCT concentrations in this study are in accordance with those in other studies $[6,15]$. The method used in this study was able to detect low PCT concentrations (sensitivity of $0.06 \mathrm{ng} / \mathrm{mL}$ ) more sensitively than the older LUMItest assay (B.R.A.H.M.S), which has a detection limit of 0.3 to $0.5 \mathrm{ng} / \mathrm{mL}$ [32] and was used in many previous studies $[15,16]$. The cutoff limit for PCT is often set at approximately $1 \mathrm{ng} / \mathrm{mL}$ in studies detecting sepsis from other causes of systemic inflammatory response $[15,16,33,34]$. The median PCT concentrations in our patients were $5.0 \mathrm{ng} / \mathrm{mL}$ on the day that severe sepsis was diagnosed and $6.5 \mathrm{ng} / \mathrm{mL}$ in patients with septic shock. These concentrations are concordant with other studies in patients with diagnosed severe sepsis [20,35]. In our study, as many as $22.7 \%$ of patients $(55 / 242)$ had a first PCT concentration of below $1 \mathrm{ng} / \mathrm{mL}$. Nobre and colleagues [20] found that $19.1 \%$ of severely septic patients (13/68) had equally low PCT concentrations. Notably, $15 \%$ of patients with clinically diagnosed severe sepsis had low PCT concentrations both at study entry and at 72 hours.

PCT concentrations were higher in patients with blood culture-positive severe sepsis, septic shock, or 


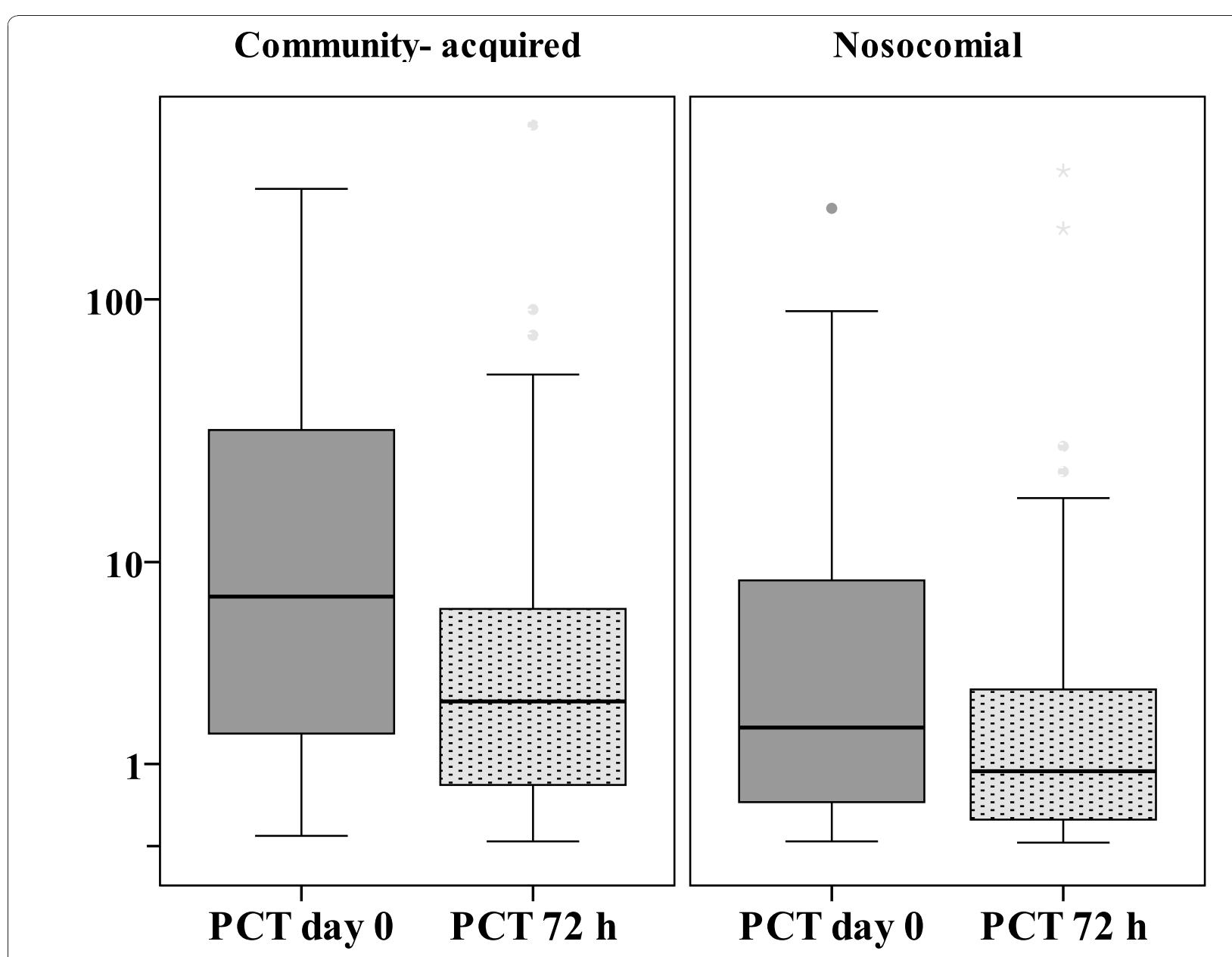

Figure 2 Procalcitonin (PCT) concentrations in patients with community-acquired or nosocomial infections. $P=0.001$ on day 0 and $P=$ 0.003 at 72 hours between the patient groups. PCT concentrations are shown in logarithmic scale and are presented in nanograms per milliliter.

acute renal failure. High PCT concentrations in septic shock or blood culture-positive patients were found in other studies [15,36,37]. Using PCT levels of greater than $0.5 \mathrm{ng} / \mathrm{mL}$ as the diagnostic criteria could decrease the need for blood cultures in patients with communityacquired pneumonia by $52 \%$ while still identifying $88 \%$ of positive cultures [38]. In our more heterogeneous patient population, the PCT concentration cutoff for $88 \%$ sensitivity was higher $(2.7 \mathrm{ng} / \mathrm{mL})$, with a specificity of 53\%. Meisner and colleagues [39] found that higher SOFA scores were associated with higher PCT concentrations in 40 patients, but in our larger study, we found no association with overall organ dysfunction, even with increasing concentrations.

We found higher PCT concentrations in patients with community-acquired infections than in patients with nosocomial infections. Few studies have made comparisons between these patient groups. However, previous sepsis may have an influence on decreasing PCT values compared with patients with primary sepsis [40]. In that study, all cases of secondary sepsis were nosocomial in origin, but $64 \%$ of primary sepsis cases were communityacquired. We had significantly more intra-abdominal infections in the nosocomial group; of these patients, $52.9 \%$ had ongoing antimicrobial treatment. In general, PCT concentrations may also be influenced by the organism causing infection [41,42].

PCT concentrations in intra-abdominal infections can be useful when deciding the time frame for on-demand laparotomy, and a PCT ratio cutoff value of 1.03 has been proposed to predict successful elimination of the intra-abdominal infection source [43]. In postoperative critically ill patients, the cutoff point for PCT concentration was $1.44 \mathrm{ng} / \mathrm{mL}$ to detect worse outcome [44], which may be due to infection and possible unsuccessful control of the source.

In general, the severity of the inflammatory response, the appropriate antimicrobial therapy, the timing for antimicrobial administration, and adequate source control all have influence on infection healing and PCT 


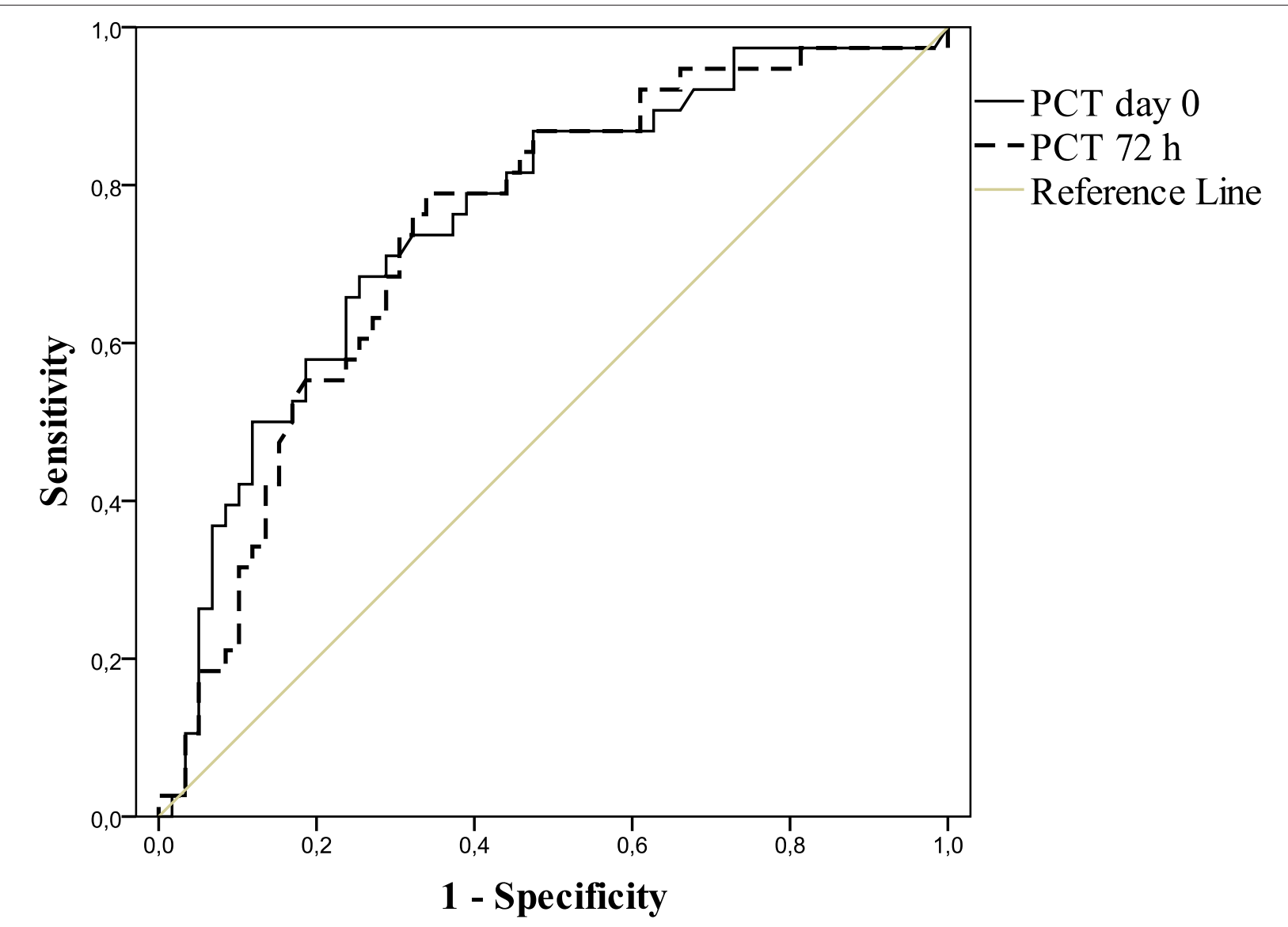

Figure 3 Receiver operating characteristic curve for procalcitonin (PCT) concentration and positive blood culture. Areas under the curve are 0.76 (95\% confidence interval [Cl] 0.66 to $0.86, P<0.001$ ) for PCT on day 0 and 0.74 ( $95 \%$ Cl 0.64 to $0.84, P<0.001)$ for PCT at 72 hours.

decrease. These variable factors may explain the differences in PCT concentrations in patients with community-acquired or nosocomial infections.

In our study, unlike in the study by Clec'h and colleagues [15], single PCT concentrations did not predict mortality; however, CRP was equally poor at predicting outcome in both studies. In a French study, the first PCT concentration did not predict outcome, but concentrations were higher in nonsurvivors measured 3 days later [14]. Jensen and colleagues [16] studied the predictive value of PCT in critically ill patients in general and found that concentrations over $1 \mathrm{ng} / \mathrm{mL}$ predicted worse outcome. This is in accordance with other studies' cutoff limits that were used to discriminate patients with severe infections from those without severe infections.

In recent studies, a cutoff value of $1 \mathrm{ng} / \mathrm{mL}$ was used $[20,45]$ to reduce antibiotic exposure or the length of antibiotic treatment was based on PCT cutoff ranges or decreasing PCT concentrations. In the ProHOSP study, antibiotic administration was strongly encouraged for patients with LRTIs and PCT concentrations of higher than $0.5 \mathrm{ng} / \mathrm{mL}$ [18]. Patients in this study had community-acquired pneumonia or LRTI and were not necessarily critically ill [18]. However, in critically ill patients, PCT-guided termination of antibiotic treatment was used without worsening outcome $[19,45]$.

Our study has some limitations. Owing to unavailable consent, blood samples were drawn from only half of the patients $(51.2 \%)$ in the Finnsepsis study, and $\triangle$ PCT could be calculated from only one third of all patients (155/470, $33 \%)$. However, the patients with PCT measurements did not differ from the other patients with regard to demographic data or severity of illness. Furthermore, we measured PCT concentrations at only two time points: on the day severe sepsis was diagnosed and 72 hours afterwards, rather than serially during the entire length of stay in the ICU. On the other hand, our study, with 242 patients, is one of the largest published studies of PCT measurements in clinically diagnosed severe sepsis patients who were treated in intensive care. Finally, antibiotic treatment was not adjusted on the basis of PCT, but of clinical response and CRP values. Thus, the outcome was not biased or affected by PCT measurements. 


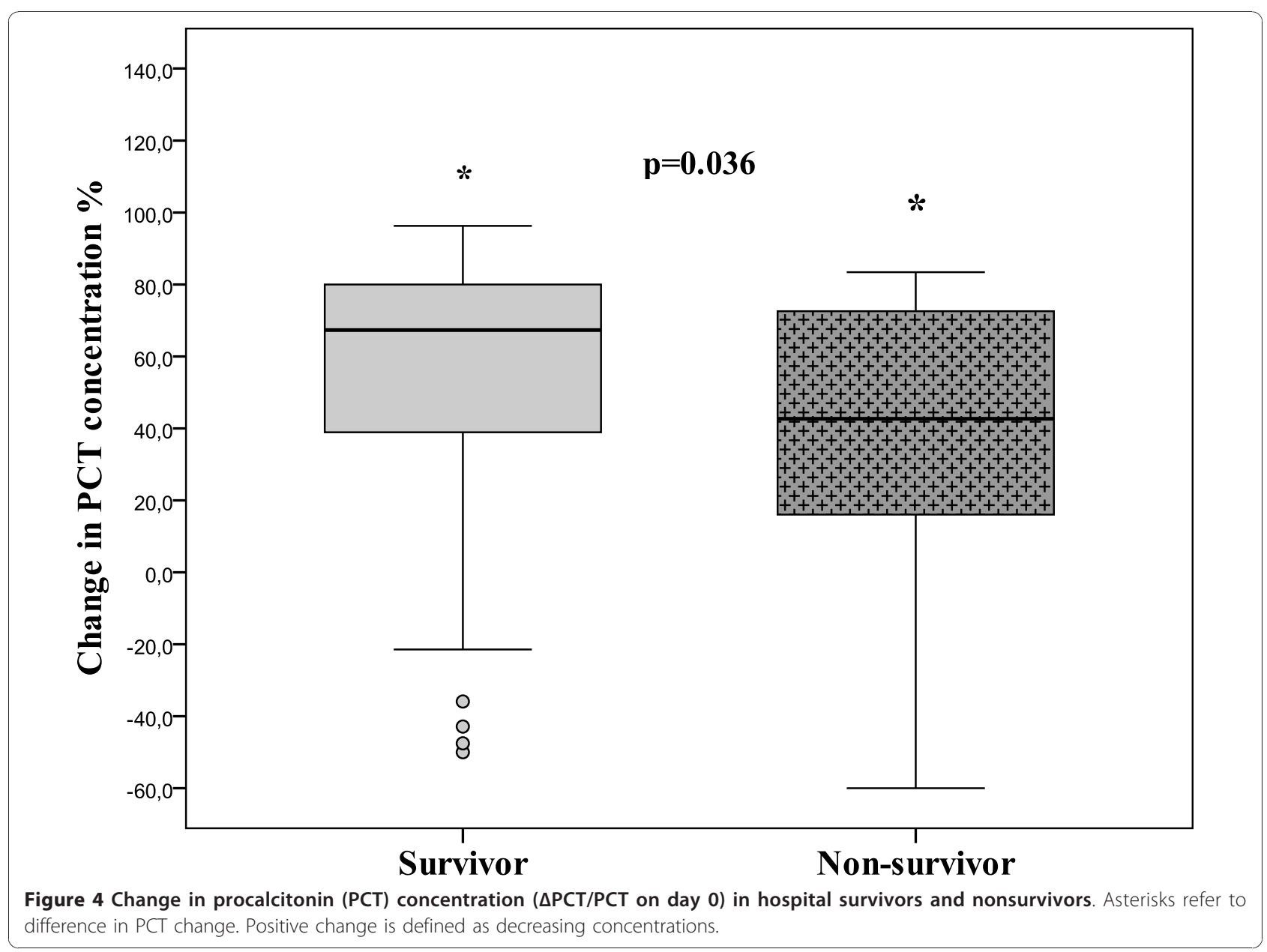

\section{Conclusions}

PCT concentrations are elevated in patients with blood culture-positive infections and septic shock, but single values have no predictive value for patient outcome. However, a decrease in PCT concentrations may be associated with a favorable outcome in patients with severe sepsis. Because of a substantial proportion of severe sepsis patients with low PCT concentrations on admission, clinical suspicion and diagnosis of severe sepsis cannot be replaced with PCT measurements.

\section{Key messages}

- Procalcitonin (PCT) concentrations are elevated in patients with severe sepsis, especially with positive blood culture infections or with septic shock.

- Some patients with severe sepsis may have low PCT levels and the diagnosis cannot be based only on PCT concentrations.

- A substantial decrease in PCT concentration seems to be more important for survival than individual values.

\section{Abbreviations}

APACHE II: Acute Physiology and Chronic Health Evaluation II; AUC: area under the curve; Cl: confidence interval; CRP: C-reactive protein; ICU: intensive care unit; IL-6: interleukin-6; IQR: interquartile range; LRTI: lower respiratory tract infection; $P C T$ : procalcitonin; ROC: receiver operating characteristic; SAPS II: Simplified Acute Physiology Score I; SOFA: Sequential Organ Failure Assessment.

\section{Acknowledgements}

The authors would like to acknowledge all investigators and study nurses taking part in the Finnsepsis study at the participating hospitals (hospital: investigator, study nurses): (1) Satakunta Central Hospital: Vesa Lund, Marika Vettenranta, Päivi Tuominen; (2) East Savo Central Hospital: Markku Suvela, Sari Hirvonen, Anne-Marja Turkulainen; (3) Central Finland Central Hospital: Raili Laru-Sompa, Tiina Kirkhope; (4) South Savo Central Hospital: Heikki Laine, Aki Savinen, Pekka Kettunen; (5) North Karelia Central Hospital: Sari Karlsson, Jaana Kallinen, Vesa Parviainen; (6) Seinäjoki Central Hospital: Kari Saarinen, Johanna Kristola, Niina Tuominen; (7) South Karelia Central Hospital: Seppo Hovilehto, Sari Melto, Marjut Repo; (8) Kainuu Central Hospital: Tuula Korhonen, Ulla Koponen, Kirsti Pomell; (9) Vaasa Central Hospital: Pentti Kairi, Marianne Ström; (10) Kanta-Häme Central Hospital: Ari Alaspää, Elina Helminen; (11) Lappi Central Hospital: Outi Kiviniemi, Tarja Laurila; (12) Midde Pohjanmaa Central Hospital: Tadeusz Kaminski, Tea Verronen; (13)

Kymenlaakso Central Hospital: Jussi Pentti, Seija Alila; (14) Helsinki University Hospital: Ville Pettilä, Marjut Varpula, Marja Hynninen, Elina Kolho, Marja Pere 
(, Maiju Salovaara; (15) Helsinki University Hospital (Jorvi): Tero Varpula, Mirja Vauramo; (16) Helsinki University Hospital (Peijas): Rita Linko, Kimmo Kuusisto; (17) Tampere University Hospital: Esko Ruokonen, Pertti Arvola, Minna-Liisa Peltola, Anna-Liina Korkala, Jani Heinilä; (18) Kuopio University Hospital: Ilkka Parviainen, Seija Laitinen, Elina Halonen, Mirja Tiainen, Heikki Ahonen; (19) Oulu University Hospital: Tero Ala-Kokko, Jouko Laurila, Tarja Lamberg, Sinikka Sälkiö; (20) West Pohja Central Hospital: Jorma Heikkinen, Kirsi Heinonen. This study was supported by Helsinki University Hospital EVO grant T102010070

\section{Author details}

'Department of Intensive Care Medicine, Tampere University Hospital, Teiskontie 35, 33521 Tampere, Finland. 'Department of Clinical Chemistry, University of Eastern Finland and Eastern Finland Laboratory Centre, Puijonlaaksontie 2, 70211 Kuopio, Finland. ${ }^{3}$ Division of Anaesthesia and Intensive Care Medicine, Department of Surgery, Helsinki University Hospital, Haartmaninkatu 4, 00029 HUS, Helsinki, Finland. ${ }^{4}$ Department of Anaesthesia and Intensive Care Medicine, Kymenlaakso Central Hospital, Kotkantie 41, 48210 Kotka, Finland. ${ }^{5}$ Division of Infectious Diseases, Department of Medicine, Helsinki University Hospital, Haartmaninkatu 4, 00029 HUS, Helsinki, Finland. ${ }^{6}$ Department of Intensive Care Medicine, Kuopio University Hospital, Puijonlaaksontie 2, 70211 Kuopio, Finland.

\section{Authors' contributions}

SK contributed the idea and design of the Finnsepsis study and this substudy, analyzed the data, and wrote the initial manuscript. VP and ER contributed the idea and design of the Finnsepsis study and this substudy and contributed to the drafts of the manuscript. EK contributed the idea and design of the Finnsepsis study and this substudy. MH, SV, and KP helped to carry out the analyses and contributed to the manuscript. SA collected the data and contributed to the drafting of the manuscript. All authors read and approved the final version of the manuscript.

\section{Competing interests}

The authors declare that they have no competing interests.

Received: 12 August 2010 Revised: 2 November 2010

Accepted: 15 November 2010 Published: 15 November 2010

\section{References}

1. Kumar A, Roberts D, Wood KE, Light B, Parrillo JE, Sharma S, Suppes R Feinstein D, Zanotti S, Taiberg L, Gurka D, Kumar A, Cheang M: Duration of hypotension before initiation of effective antimicrobial therapy is the critical determinant of survival in human septic shock. Crit Care Med 2006, 34:1589-1596.

2. Rivers E, Nguyen B, Havstad S, Ressler J, Muzzin A, Knoblich B, Peterson E, Tomlanovich M, Early-Goal-Directed Therapy Collaborative Group: Early goal-directed therapy in the treatment of severe sepsis and septic shock. N Engl J Med 2001, 345:1368-1377.

3. Kofoed K, Andersen O, Kronborg G, Tvede M, Petersen J, Eugen-Olsen J, Larsen K: Use of plasma C-reactive protein, procalcitonin, neutrophils, macrophage migration inhibitory factor, soluble urokinase-type plasminogen activator receptor, and soluble triggering receptor expressed on myeloid cells- 1 in combination to diagnose infections: a prospective study. Crit Care 2007, 11:R38.

4. Silvestre J, Povoa P, Coelho L, Almeida E, Moreira P, Fernandes A, Mealha R, Sabino $\mathrm{H}$ : Is C-reactive protein a good prognostic marker in septic patients? Intensive Care Med 2009, 35:909-913.

5. Jacobs JW, Lund PK, Potts JT Jr, Bell NH, Habener JF: Procalcitonin is a glycoprotein. J Biol Chem 1981, 256:2803-2807.

6. Assicot M, Gendrel D, Carsin H, Raymond J, Guilbaud J, Bohuon C: High serum procalcitonin concentrations in patients with sepsis and infection. Lancet 1993, 341:515-518.

7. Dandona P, Nix D, Wilson MF, Aljada A, Love J, Assicot M, Bohuon C: Procalcitonin increase after endotoxin injection in normal subjects. J Clin Endocrinol Metab 1994, 79:1605-1608.

8. Maier M, Wutzler S, Lehnert M, Szermutzky M, Wyen H, Bingold T, Henrich D, Walcher F, Marzi I: Serum procalcitonin levels in patients with multiple injuries including visceral trauma. J Trauma 2009, 66:243-249.

9. Picariello C, Lazzeri C, Chiostri M, Gensini G, Valente S: Procalcitonin in patients with acute coronary syndromes and cardiogenic shock submitted to percutaneous coronary intervention. Intern Emerg Med 2009, 4:403-408.

10. Schuetz P, Affolter B, Hunziker S, Winterhalder C, Fischer M, Balestra GM, Hunziker $P$, Marsch S: Serum procalcitonin, C-reactive protein and white blood cell levels following hypothermia after cardiac arrest: a retrospective cohort study. Eur J Clin Invest 2010, 40:476-481.

11. Bonaci-Nikolic B, Jeremic I, Nikolic M, Andrejevic S, Lavadinovic L: High procalcitonin in a patient with drug hypersensitivity syndrome. Intern Med 2009, 48:1471-1474.

12. Sarbinowski R, Arvidsson S, Tylman M, Oresland T, Bengtsson A: Plasma concentration of procalcitonin and systemic inflammatory response syndrome after colorectal surgery. Acta Anaesthesiol Scand 2005, 49:191-196.

13. Müller B, White JC, Nylén ES, Snider RH, Becker KL, Habener JF: Ubiquitous expression of the calcitonin-i gene in multiple tissues in response to sepsis. J Clin Endocrinol Metab 2001, 86:396-404.

14. Charles PE, Tinel C, Barbar S, Aho S, Prin S, Doise JM, Olsson NO, Blettery B, Quenot JP: Procalcitonin kinetics within the first days of sepsis: relationship with the appropriateness of antibiotic therapy and the outcome. Crit Care 2009, 13:R38.

15. Clec'h C, Ferriere F, Karoubi P, Fosse JP, Cupa M, Hoang P, Cohen Y: Diagnostic and prognostic value of procalcitonin in patients with septic shock. Crit Care Med 2004, 32:1166-1169.

16. Jensen JU, Heslet $L$, Jensen TH, Espersen K, Steffensen P, Tvede M: Procalcitonin increase in early identification of critically ill patients at high risk of mortality. Crit Care Med 2006, 34:2596-2602.

17. Venkatesh B, Kennedy P, Kruger PS, Looke D, Jones M, Hall J, Barruel GR Changes in serum procalcitonin and C-reactive protein following antimicrobial therapy as a guide to antibiotic duration in the critically ill: a prospective evaluation. Anaesth Intensive Care 2009, 37:20-26.

18. Schuetz P, Christ-Crain M, Thomann R, Falconnier C, Wolbers M, Widmer I, Neidert S, Fricker T, Blum C, Schild U, Regez K, Schoenenberger R, Henzen C, Bregenzer T, Hoess C, Krause M, Bucher HC, Zimmerli W, Mueller B, ProHOSP Study Group: Effect of procalcitonin-based guidelines vs standard guidelines on antibiotic use in lower respiratory tract infections: the ProHOSP randomized controlled trial. JAMA 2009, 302:1059-1066.

19. Bouadma L, Luyt CE, Tubach F, Cracco C, Alvarez A, Schwebel C, Schortgen F, Lasocki S, Veber B, Dehoux M, Bernard M, Pasquet B, Régnier B, Brun-Buisson C, Chastre J, Wolff M, Prorata trial group: Use of procalcitonin to reduce patients' exposure to antibiotics in intensive care units (PRORATA trial): a multicentre randomised controlled trial. Lancet 2010, 375:463-474

20. Nobre V, Harbarth S, Graf JD, Rohner P, Pugin J: Use of procalcitonin to shorten antibiotic treatment duration in septic patients: a randomized trial. Am J Respir Crit Care Med 2008, 177:498-505.

21. Tang BM, Eslick GD, Craig JC, McLean AS: Accuracy of procalcitonin for sepsis diagnosis in critically ill patients: systematic review and metaanalysis. Lancet Infect Dis 2007, 7:210-217.

22. Uzzan B, Cohen R, Nicolas P, Cucherat M, Perret GY: Procalcitonin as a diagnostic test for sepsis in critically ill adults and after surgery or trauma: a systematic review and meta-analysis. Crit Care Med 2006, 34:1996-2003.

23. Kumar A, Ellis P, Arabi Y, Roberts D, Light B, Parrillo JE, Dodek P, Wood G, Kumar A, Simon D, Peters C, Ahsan M, Chateau D, Cooperative Antimicrobial Therapy of Septic Shock Database Research Group: Initiation of inappropriate antimicrobial therapy results in a fivefold reduction of survival in human septic shock. Chest 2009, 136:1237-1248.

24. Meisner M, Tschaikowsky K, Hutzler A, Schick C, Schüttler J: Postoperative plasma concentrations of procalcitonin after different types of surgery. Intensive Care Med 1998, 24:680-684

25. Karlsson S, Varpula M, Ruokonen E, Pettilä V, Parviainen I, Ala-Kokko TI, Kolho E, Rintala EM: Incidence, treatment, and outcome of severe sepsis in ICU-treated adults in Finland: the Finnsepsis study. Intensive Care Med 2007, 33:435-443.

26. Bone RC, Balk RA, Cerra FB, Dellinger RP, Fein AM, Knaus WA, Schein RM, Sibbald WJ: Definitions for sepsis and organ failure and guidelines for the use of innovative therapies in sepsis. The ACCP/SCCM Consensus Conference Committee. American College of Chest Physicians/Society of Critical Care Medicine. Chest 1992, 101:1644-1655. 
27. Knaus WA, Draper EA, Wagner DP, Zimmerman JE: APACHE II: a severity of disease classification system. Crit Care Med 1985, 13:818-829.

28. Le Gall JR, Lemeshow S, Saulnier F: A new Simplified Acute Physiology Score (SAPS II) based on a European/North American multicenter study. JAMA 1993, 270:2957-2963.

29. Vincent JL, Moreno R, Takala J, Willatts S, De Mendonça A, Bruining H, Reinhart CK, Suter PM, Thijs LG: The SOFA (Sepsis-related Organ Failure Assessment) score to describe organ dysfunction/failure. On behalf of the Working Group on Sepsis-Related Problems of the European Society of Intensive Care Medicine. Intensive Care Med 1996, 22:707-710.

30. Moreno R, Vincent JL, Matos R, Mendonça A, Cantraine F, Thijs L, Takala J, Sprung C, Antonelli M, Bruining $H$, Willatts S: The use of maximum SOFA score to quantify organ dysfunction/failure in intensive care. Results of a prospective, multicentre study. Working Group on Sepsis related Problems of the ESICM. Intensive Care Med 1999, 25:686-696.

31. Meisner M, Brunkhorst FM, Reith HB, Schmidt J, Lestin HG, Reinhart K: Clinical experiences with a new semi-quantitative solid phase immunoassay for rapid measurement of procalcitonin. Clin Chem Lab Med 2000, 38:989-995.

32. Whang KT, Steinwald PM, White JC, Nylen ES, Snider RH, Simon GL, Goldberg RL, Becker KL: Serum calcitonin precursors in sepsis and systemic inflammation. J Clin Endocrinol Metab 1998, 83:3296-3301.

33. Mokart D, Merlin M, Sannini A, Brun JP, Delpero JR, Houvenaeghel G, Moutardier V, Blache JL: Procalcitonin, interleukin 6 and systemic inflammatory response syndrome (SIRS): early markers of postoperative sepsis after major surgery. Br J Anaesth 2005, 94:767-773.

34. Harbarth S, Holeckova K, Froidevaux C, Pittet D, Ricou B, Grau GE, Vadas L, Pugin J, Geneva Sepsis Network: Diagnostic value of procalcitonin, interleukin-6, and interleukin-8 in critically ill patients admitted with suspected sepsis. Am J Respir Crit Care Med 2001, 164:396-402.

35. Dorizzi RM, Polati E, Sette P, Ferrari A, Rizzotti P, Luzzani A: Procalcitonin in the diagnosis of inflammation in intensive care units. Clin Biochem 2006, 39:1138-1143.

36. Brunkhorst FM, Wegscheider K, Forycki ZF, Brunkhorst R: Procalcitonin for early diagnosis and differentiation of SIRS, sepsis, severe sepsis, and septic shock. Intensive Care Med 2000, 26 Suppl 2:S148-S152.

37. Nakamura A, Wada H, Ikejiri M, Hatada T, Sakurai H, Matsushima Y, Nishioka J, Maruyama K, Isaji S, Takeda T, Nobori T: Efficacy of procalcitonin in the early diagnosis of bacterial infections in a critical care unit. Shock 2009, 31:586-591.

38. Müller F, Christ-Crain M, Bregenzer T, Krause M, Zimmerli W, Mueller B, Schuetz P, PreHOSP Study Group: Procalcitonin levels Predict Bacteremia in Patients with community-acquired Pneumonia: A prospective cohort trial. Chest 2010, 138:121-129.

39. Meisner M, Tschaikowsky K, Palmaers T, Schmidt J: Comparison of procalcitonin (PCT) and C-reactive protein (CRP) plasma concentrations at different SOFA scores during the course of sepsis and MODS. Crit Care 1999, 3:45-50

40. Charles PE, Ladoire S, Snauwaert A, Prin S, Aho S, Pechinot A, Olsson NO, Blettery B, Doise JM, Quenot JP: Impact of previous sepsis on the accuracy of procalcitonin for the early diagnosis of blood stream infection in critically ill patients. BMC Infect Dis 2008, 8:163.

41. Charles PE, Ladoire S, Aho S, Quenot JP, Doise JM, Prin S, Olsson NO, Blettery B: Serum procalcitonin elevation in critically ill patients at the onset of bacteremia caused by either Gram negative or Gram positive bacteria. BMC Infect Dis 2008, 8:38.

42. Martini A, Gottin L, Menestrina N, Schweiger V, Simion D, Vincent JL: Procalcitonin levels in surgical patients at risk of candidemia. J Infect 2010, 60:425-430.

43. Novotny AR, Emmanuel K, Hueser N, Knebel C, Kriner M, Ulm K, Bartels H, Siewert JR, Holzmann B: Procalcitonin ratio indicates successful surgical treatment of abdominal sepsis. Surgery 2009, 145:20-26.

44. Schneider CP, Yilmaz Y, Kleespies A, Jauch KW, Hartl WH: Accuracy of procalcitonin for outcome prediction in unselected postoperative critically ill patients. Shock 2009, 31:568-573.
45. Hochreiter M, Kohler T, Schweiger AM, Keck FS, Bein B, von Spiegel T, Schroeder S: Procalcitonin to guide duration of antibiotic therapy in intensive care patients: a randomized prospective controlled trial. Crit Care 2009, 13:R83

doi:10.1186/cc9327

Cite this article as: Karlsson et al:: Predictive value of procalcitonin decrease in patients with severe sepsis: a prospective observational study. Critical Care 2010 14:R205.

\section{Submit your next manuscript to BioMed Central and take full advantage of:}

- Convenient online submission

- Thorough peer review

- No space constraints or color figure charges

- Immediate publication on acceptance

- Inclusion in PubMed, CAS, Scopus and Google Scholar

- Research which is freely available for redistribution

Submit your manuscript at www.biomedcentral.com/submit
C Biomed Central 